\title{
Pengembangan Penanganan Pascapanen melalui Kelembagaan Pertanian sebagai Upaya Pembangunan Pertanian dan Pedesaan
}

\author{
Development of Postharvest Handling through Agricultural Institutions as an Effort for Agricultural and Rural \\ Development
}

Fitri Lesia Herdini ${ }^{*}$, Masduki ${ }^{2}$

Citation: Herdini, F.L.; Masduki, M. Pengembangan Penanganan Pascapanen melalui Kelembagaan Pertanian sebagai Upaya Pembangunan Pertanian dan Pedesaan. Buletin Pemberdayaan Masyarakat dan Desa 2021, 1(1), 32-37. https://doi.org/10.21107/bpmd.v1i1. 12023

Received: July, 2021

Accepted: August, 2021

Published: September, 2021

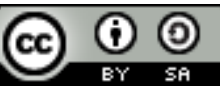

Copyright: (c) 2021 by the authors. Submitted for possible open access publication under the terms and conditions of the Creative Commons Attribution (CC BY SA) license (https://creativecommons.org/license s/by-sa/4.0/).

\author{
${ }^{1}$ Ekonomi Pembangunan, Universitas Trunojoyo Madura; J1 Raya Telang, Kamal Bangkalan Kode Pos 69162; \\ 2 Sastra Inggris, Universitas Trunojoyo Madura; Jl Raya Telang, Kamal Bangkalan Kode Pos 69162; \\ *Correspondence: fitrilesiaherdini@gmail.com
}

\begin{abstract}
Abstrak: Penulisan ini bertujuan untuk mengetahui upaya pembangunan pertanian melalui kelembagaan guna pengembangan penanganan pascapanen. Penulisan ini menggunakan metode tinjauan literature. Dari hasil dan diskusi dapat disimpulkan bahwa pentingnya peranan pertanian menempatkan kelembagaan pertanian sebagai pemenuhan kebutuhan masyarakat terkait dengan pengelolaan atau manajemen bidang pertanian di pedesaan. Perumusan kebijakan pertanian yang pro petani merupakan pilihan yang tepat dan harus berjalan dengan sukses agar pembangunan masyarakat petani di wilayah pedesaan dapat terealisasikan. Adapun beberapa tujuan kebijakan pertanian adalah memajukan pertanian petani, mengusahakan supaya pertanian lebih produktif dan menghasilkan produk yang efisien serta meningkatkan kemakmuran petani menjadi tujuan yang harus diutamakan. Terutama pada pemanenan atau pascapanen memerlukan dukungan kelembagaan pertanian sebagai upaya menyebarkan informasi teknologi, penyuluhan, informasi pasar, dan pembinaan beserta kebijakan yang tertulis untuk memberikan kepastian usaha pertanian.
\end{abstract}

Keywords: pembangunan pertanian, penanganan pascapanen, kelembagaan pertanian

Abstract: This writing aims to determine agricultural development efforts through institutions in order to develop post-harvest handling. This writing uses the literature review method. From the results and discussion, it can be concluded that the importance of the role of agriculture in placing agricultural institutions as meeting community needs related to the management or management of agriculture in rural areas. The formulation of pro-farmer agricultural policies is the right choice and must run successfully so that the development of farming communities in rural areas can be realized. As for some of the objectives of agricultural policies are to promote farmer agriculture, make agriculture more productive and produce efficient products and increase the prosperity of farmers are goals that must be prioritized. Especially in harvesting or post-harvest, agricultural institutional support is needed as an effort to disseminate technological information, extension, market information, and guidance along with written policies to provide certainty in agricultural business.

Keywords: agricultural development, post-harvest handling, agricultural institutions

\section{PENDAHULUAN}

Masyarakat pertanian di daerah pedesaan umumnya termasuk penduduk menengah kebawah dan mayoritas dalam proses produksi hanya mengandalkan tenaga kerja sebagai sumberdaya utama. Produktivitas dalam hal pertanian diharapkan mampu memberikan peluang bagi peningkatan pendapatan dan kesejahteraan terutama pada buruh tani. Masuknya ekonomi kapitalis ke wilayah pedesaan berupa penggunaan teknologi modern dan sistem pasar (mengutamakan efisien) serta perubahan nilai ekonomi menyebabkan tingginya tingkat konversi tanah dari pertanian ke non-pertanian. 
Hal tersebut berdampak pada hilangnya kesempatan kerja bagi sebagian buruh tani dan layunya ikatan-ikatan sosial yang sudah tertanam dalam masyarakat pedesaan (Roosgandha Elizabeth, 2007).

Perumusan kebijakan pertanian yang pro petani merupakan pilihan yang tepat dan harus berjalan dengan sukses agar pembangunan masyarakat petani di wilayah pedesaan dapat terealisasikan. Adapun beberapa tujuan kebijakan pertanian adalah memajukan pertanian petani, mengusahakan supaya pertanian lebih produktif dan menghasilkan produk yang efisien serta meningkatkan kemakmuran petani menjadi tujuan yang harus diutamakan. Sedangkan saat ini yang masih menjadi masalah utama petani dan perlunya perhatian ialah pengolahan pascapanen untuk meningkatkan efisiensi dan meminimalisir terjadinya kehilangan hasil produk pertanian. Berkaitan dengan hal tersebut kegiatan pascapanen khususnya padi meliputi 1) pemanenan, 2) perontokan, 3) perawatan atau pengeringan, 4) pengengkutan, 5) pengilingan, 6) penyimpanan, 7) standarisasi mutu, 8)pengolahan, dan 9) penanganan limbah. Penanganan pascapanen yang sesuai dan baik akan berdampak positif terhadap kualitas output (Setyono, 2010). Cakupan aspek guna pengembangan pada teknologi pascapanen dan sistem pemanenan meliputi aspek teknis, sosialekonomi, budaya, dan pengaruh kelembagaan melalui kebijakan perangkat hukum yang menguntungkan berbagai pihak. Kelembagaan pertanian dapat memenuhi kebutuhan masyarakat terkait dengan pengelolaan atau manajemen bidang pertanian di pedesaan.

Penulisan ini bertujuan untuk mengetahui bagaimana pengembangan penanganan pascapanen sebagai upaya pembangunan pertanian melalui melalui beberapa langkah kebijakan.

\section{DISKUSI DAN HASIL}

Pembangunan pertanian apabila dijabarkan merupakan suatu akar dari pembangunan nasional sedangkan implementasinya diwajibkan sejalan dengan pembangunan sector lain. Tujuan dari pembangunan pertanian itu sendiri adalah: 1) membangun sumber daya manusia terutama petani dan/atau kelembagaan pertanian, 2) memanfaatkan pembangunan pertanian supaya berkelanjutan, 3) mengkokohkan ketahanan dan keamanan pangan, 4) meningkatkan produktivitas pertanian, 5) membangun tata kelola pertanian yang berpihak kepada petani. Sementara itu, sasarannya ialah industrialisasi dan kesejahteraan petani (Iqbal, 2007).

A.T Mosher (1965) menyampaikan argumennya bahwa ada 5 syarat mutlak pada suatu pembangunan pertanian ialah a) adanya pasar untuk hasil-hasil usaha tani, b) teknologi yang senantiasa berkembang dalam menghasilkan output secara maksimal, c) tersedianya bahan dan alat produksi secara lokal yang sesuai dengan kondisi di daerah tersebut, d) adanya penyokong petani untuk berproduksi, dan e) tersedianya sarana transportasi yang memadai.

Perkembangan teknologi pascapanen di Indonesia mengalami peningkatan walaupun berjalan lambat. Dimulai dari periode pra revolusi hijau dimana belum mengenal istilah pascapanen kemudian dilanjut pada periode revolusi hijau yang sudah menghasilkan output tinggi tetapi bermutu rendah lalu pada periode setelahnya yaitu pascaswasembada beras yang sudah mulai mendapat perhatian dari pemerintah melalui kebijakannya akan tetapi masih belum dapat mengatasi kehilangan hasil pertanian yang tinggi. Terakhir yang terjadi hingga saat ini dan cukup membuahkan hasil ialah periode reformasi dan desentralisasi yang berupaya mengembangkan teknologi pascapanen melalui pelatihan dan demonstrasi bagi para penyuluh. Hal ini terbukti dari persentase tingkat kehilangan hasil pertanian yang menurun. Keberhasilan tersebut juga tidak terlepas dari peran kelembagaan didalamnya. Dalam kehidupan komunitas petani, posisi dan fungsi kelembagaan petani merupakan institusi yang mewadahi interaksi sosial dalam suatu komunitas petani. Kelembagaan pertani juga memiliki titik strategis dalam menggerakkan sistem agribisnis di pedesaan. Maka dari itu segala sumberdaya yang mendiami pedesaan perlu diarahkan/diunggulkan dalam rangka peningkatan profesionalisme dan posisi tawar petani (kelompok tani). 
Berdasarkan penelitian yang telah dilakukan Nasrul (2012) menunjukkan signifikansi keberdayaan kelembagaan dalam pembangunan sector pertanian. Kelembagaan pertanian dalam hal ini mampu mengatasi permasalahan yang terjadi dan tidak lepas dari partisipasi masyarakat cukup tinggi melalui pemberdayaan petani yang telah dirumuskan/kesepakatan bersama. Hal ini sejalan dengan hasil berbagai pengamatan yang menyatakan bahwa pembangunan pertanian dilakukan oleh inisiatif kelembagaan atau organisasi yang merupakan kumpulan individuindividu yang memiliki tujuan sama yaitu keberhasilan pembangunan pertanian dengan berbagai tahap perencanaan dan pengimplementasiannya.

Berdasarkan penelitian yang telah dilakukan Indriana, H, dkk (2016) menunjukkan adanya kemungkinan terjadinya penyimpangan dalam relasi kelompok tani sebagai akibat dari sistem kelembagaan yang tidak jangka panjang. Faktor ynng menyebabkan kemungkinan penyimpangan tersebut adalah faktor kepemimpinan yang tidak sesuai dan kurangnya partisipasi anggota kelompok tani. Padahal kedua faktor

\section{Peran pertanian dalam pembangunan Ekonomi}

Letak dan kondisi Indonesia yang membuat lebih unggul dari daerah lain khususnya pada bidang pertanian menyebabkan pertanian mepunyai peran sangat penting dalam pembangunan ekonomi di Indonesia. Pentingnya peranan pertanian menempatkan sector pertanian pada pembangunan ekonomi yang utama dan unggulan. Pembangunan pertanian diarahkan untuk meningkatkan produksi pertanian guna memenuhi tuntutan pangan dan kebutuhan industri dalam negeri, meningkatkan pendapatan petani, meningkatkan ekspor, mendorong pemerataan kesempatan berusaha dan memperluas kesempatan kerja.

\section{Peran pembangunan pertanian terhadap ekonomi pedesaan}

Pembangunan pertanian akan meningkatkan produktivitas tanaman yang menjadi basis pembangunan ekonomi hampir seluruh negara di dunia, terutama bahan pangan, melalui intensifikasi penggunaan lahan dan pemanfaatan sumberdaya ekonomi secara optimal. Pembangunan pertanian yang diciptakan haruslah menempatkan petani sebagai subjek utama dan harus dilindungi keberadaannya. Apabila pendapatan petani ikut meningkat sekalipun tingkat harga tidak berubah maka ekonomi pedesaan akan berputar lebih baik, karena tingkat pengeluaran terhadap produk-produk non-farm juga meningkat. Pembangunan pertanian menjadi landasan utama menuju modernisasi pembangunan ekonomi, tanpa berlebihan untuk saling bersubsitusi (trade-off) antara sektor pertanian, industri dan jasa.

\section{Keterkaitan pembangunan Pertanian dan Pembangunan Ekonomi}

Menurut sadono (2002) pembangunan ekonomi adalah proses meningkatkan pendapatan per kapita penduduk suatu negara. Pembangunan ekonomi sebagai suatu proses meningkatkan ekonomi dan taraf hidup masyarakat yang diharapkan dapat terjadi secara kesinambungan dan terus menerus kearah yang lebih positif. Upaya pemerintah daerah meningkatkan kesejahteraan masyarakat dengan menggali dan mengembangkan potensi-potensi yang ada di wilayah melalui pengembangan ekonomi lokal untuk meningkatkan pembangunan ekonomi daerah terutama pada daerah pedesaan yang mana sebagian besar penduduk bermata pencaharian di bidang pertanian. Sebab apabila pengembangan pertanian berjalan baik maka pembangunan daerah juga mengalami peningkatan. Aspek-aspek yang harus disusun secara matang dalam pembangunan ekonomi daerah adalah kemampuan untuk memanfaatkan sumber daya alam maupun sumber daya manusia seefisien dan seefektif mungkin. Oleh sebab itu, segala aspek haruslah berkesinambungan untuk dirumuskan melalui sebuah kerangka kebijakan pembangunan ekonomi pertanian yang terpadu dan terencana (Junaidi \& Zulgani, 2011). 


\section{Peran kelembagaan dalam pembangunan pertanian}

Peran kelembagaan dalam kegiatan pertanian tanaman pangan khususnya padi dapat membangun dan mengembangkan sector pertanian di Indonesia (Suradisastra, 2011). Di tingkat makro, peran lembaga pertanian sangat tampak dalam program dan proyek intensifikasi dan peningkatan produksi pangan. Kegiatan pembangunan pertanian dicapai dalam bentuk program dan proyek dengan membangun kelembagaan koersif (kelembagaan yang dipaksakan), seperti Padi Sentra, Demonstrasi Massal (Demas), Bimbingan Massal (Bimas), Bimas Gotong Royong, Badan Usaha Unit Desa (BUUD), Koperasi Unit Desa (KUD), Insus, dan Supra Insus (Nasrul, 2012). Pembangunan pertanian dan pedesaan yang dinilai ideal adalah karena adanya partisipasi masyarakat desa sebagai subjek utama (Roosganda Elizabeth, 2007).

Dalam proses pengelolaan faktor-faktor produksi, hingga pengolahan hasil sangat diperlukan peran kelembagaan pertanian. Kegiatan usaha pertanian akan dicapai apabila petani mempunyai kapasitas yang mempuni. Untuk dapat mencapai produktivitas dan efisiensi yang maksimal petani harus menjalankan usaha bersama-sama. Dalam hal ini diperlukan pemahaman mendetail mengenai suatu kelembagaan di tingkat petani pedesaan. Secara tradisional, kelembagaan masyarakat petani sudah berkembang dari generasi ke generasi, namun tantangan jaman menuntut suatu kelembagaan yang lebih sesuai dalam memenuhi kebutuhan masyarakat petani. Efektifitas kelembagaan pertanian diharapkan dapat mendukung pembangunan pertanian (Anantanyu, 2011).

\section{Strategi Pengembangan kelembagaan pertanian}

Permasalahan yang sering terjadi dalam penanganan pascapanen padi ialah kenaikan tingkat kehilangan hasil serta terkait mutu yang dihasilkan. Salah satunya dengan menyusun pembentukan kelembagaan pertanian yang berkelanjutan. Misalnya saja pada pemanenan atau pascapanen memerlukan dukungan kelembagaan pertanian sebagai upaya menyebarkan informasi teknologi, penyuluhan, informasi pasar, dan pembinaan beserta kebijakan yang tertulis untuk memberikan kepastian usaha pertanian.

Dalam penelitian Indriana, H., dkk menyampaikan bahwa Hagedorn dalam Padmabadhan (2009) yang merumuskan beberapa strategi dasar pencapaian kelembagaan pertanian jangka panjang, yakni; (1) menampakkan suatu reflektivitas dibangun dengan maksud penguatan sensitivitas agar terjadi reformasi kelembagaan, (2) ikut andil dan berorganisasi didalamnya akan memberi dampak integrative, (3) menselaraskan berbagai kepentingan dan regulasi guna menyeimbangkan kekuasaan dan kontrol atas sumber daya, (4) menuangkan inovasi dan kreatifitas untuk sebuah kelembagaan secara bersama-sama (Indriana et al., 2016).

\section{Permasalahan pengembangan kelembagaan pertanian}

Petani jika berusahatani secara individu terus berada di pihak yang lemah karena petani secara individu akan mengelola usaha tani dengan luas garapan kecil dan terpencar serta kepemilikan modal yang rendah. Sehingga, pemerintah perlu memperhatikan penguatan kelembagaan lewat kelompoktani karena dengan berkelompok maka petani tersebut akan lebih kuat, baik dari segi kelembagaannya maupun permodalannya. Disisi lain pemerintah dalam tingkatanya diharuskan peduli pada permasalahan petani khususnya bagi petani yang kehilangan lahannya serta penegakan peraturan mengenai konveksi lahan yang sudah ada sehingga eksistensi lahan sekaligus keberadaan petani (Tomi Setiawan, Haidar Adi M , Yames Pakniany, 2017). Ada empat kriteria agar asosiasi petani itu kuat dan mampu berperan aktif dalam memperjuangkan hak-haknya, yaitu: (1) asosiasi harus tumbuh dari petani sendiri, (2) pengurusnya berasal dari para petani dan dipilih secara berkala, (3) memiliki kekuatan kelembagaan formal dan (4) bersifat partisipatif. Dengan terbangunnya kesadaran seperti diatas, maka diharapkan petani mampu berperan sebagai 
kelompok yang kuat dan mandiri, sehingga petani dapat meningkatkan pendapatannya dan memiliki akses pasar dan akses perbankan.

\section{KESIMPULAN}

Hubungan kelembagaan pertanian dengan pembangunan pertanian memilikitujuan akhir yang sama, yaitu meningkatkan pembangunan sektor dalam konteks regional. Pentingnya peranan pertanian menempatkan sector pertanian pada pembangunan ekonomi yang utama dan unggulan. Pembangunan pertanian diarahkan untuk meningkatkan produksi pertanian guna memenuhi tuntutan pangan dan kebutuhan industri dalam negeri, meningkatkan pendapatan petani, meningkatkan ekspor, mendorong pemerataan kesempatan berusaha dan memperluas kesempatan kerja. Apabila pendapatan petani ikut meningkat sekalipun tingkat harga tidak berubah maka ekonomi pedesaan akan berputar lebih baik, karena tingkat pengeluaran terhadap produk-produk non-farm juga meningkat. Upaya pemerintah daerah meningkatkan kesejahteraan masyarakat dengan menggali dan mengembangkan potensi-potensi yang ada di wilayah melalui pengembangan ekonomi lokal untuk meningkatkan pembangunan ekonomi daerah terutama pada daerah pedesaan yang mana sebagian besar penduduk bermata pencaharian di bidang pertanian. Peran kelembagaan dalam kegiatan pertanian tanaman pangan khususnya padi dapat membangun dan mengembangkan sector pertanian di Indonesia

Berbagai pilihan strategi untuk dikembangkan guna mempercepat pembangunan sector pertanian salah satunya ialah pemberdayaan kelembagaan pertanian daerah. Keberhasilan penerapan suatu kelembagaan pertanian tidak hanya diukur dengan nilai tambah ekonomi, namun harus mempertimbangkan peran dan fungsi nilai-nilai sosial budaya secara keseluruhan di suatu daerah. Intervensi pemerintah dalam pengembangan kelembagaan pertanian untuk kedepannya masih diperlukan. Campur tangan pemerintah haruslah bersifat memfasilitasi untuk mendorong pertumbuhan kelembagaan yang bersifat kohesif. Pemerintah perlu memperhatikan penguatan kelembagaan lewat kelompoktani karena dengan berkelompok maka petani tersebut akan lebih kuat, baik dari segi kelembagaannya maupun permodalannya.

\section{DAFTAR PUSTAKA}

Arifin, Bustanul. 2005. Pembangunan Pertanian Paradigma Kebijakan dan Strategi Revitalisasi. Jakarta: Gramedia $\begin{array}{llllll}\text { Widiasarana } & \text { Indonesia. } & \text { Diakses } & \text { pada } & 2 & \text { Januari }\end{array}$ (https://books.google.co.id/books?hl=en\&lr=\&id=b3elyNIe9AUC\&oi=fnd\&pg=PA1\&dq=Strategi+Kebijakan+Pe mbangunan+Pertanian+dan+Pedesaan\&ots=bJ1i-WOYV4\&sig= gv3xNA2nbRKm Hzg8crtRa-

L8o\&redir esc=y\#v=onepage\&q=Strategi\%20Kebijakan\%20Pembangunan\%20Pertanian\%20dan\%20Pedesaan\&f =false)

Anantanyu, S. (2011). Kelembagaan Petani: Peran Dan Strategi Pengembangan Kapasitasnya. SEPA, 7(2), 102-109.

Elizabeth, Roosganda. (2007). Penguatan Dan Pemberdayaan Kelembagaan Petani Mendukung Pengembangan Agribisnis Kedelai. Pusat Analisis Sosial Ekonomi Dan Kebijakan Pertanian, 70, 165-173.

Elizabeth, Roosgandha. (2007). Revitalisasi ketenagakerjaan dan kesempatan kerja terkait strategi dan kebijakan pembangunan pertanian dan pedesaan 1. Jurnal Sosial Ekonomi Pertanian, 1-25.

Indriana, H., A Kinseng, R., \& Adriana, G. (2016). Dinamika Kelembagaan Pertanian Organik Menuju Pembangunan Berkelanjutan. Jurnal Sosiologi Pedesaan, 4(2), 192-207. https://doi.org/10.22500/sodality.v4i2.13652

Iqbal, M. (2007). Analisis Peran Pemangku Kepentingan dan Implementasinya Dalam Pembangunan Pertanian. Jurnal Litbang Pertanian, 26(3), 89-99. http://pustaka.litbang.pertanian.go.id/publikasi/p3263071.pdf

Junaidi, \& Zulgani. (2011). Peranan Sumberdaya Ekonomi dalam Pembangunan Ekonomi Daerah. Jurnal Pembangunan 
Daerah Edisi III, 0(0), 27-33. http://repository.unja.ac.id/id/eprint/239

Nasrul, W. (2012). Pengembangan Kelembagaan Pertanian Untuk Peningkatan Kapasitas Petani Terhadap Pembangunan Pertanian. Menara Ilmu, 3(29), 166-174.

Setyono, A. (2010). Perbaikan Teknologi Pascapanen dalam Upaya Menekan Kehilangan Hasil Padi. Pengembangan Inovasi Pertanian, 3(3), 212-226.

Suradisastra, K. (2011). Revitalisasi Kelembagaan Untuk Mempercepat Pembangunan Sektor Pertanian Dalam Era Otonomi Daerah. Pengembangan Inovasi Pertanian, 4(2), 118-136.

Tomi Setiawan, Haidar Adi M, Yames Pakniany, dan I. R. . M. (2017). PELURUHAN KELEMBAGAAN PERTANIAN DI WILAYAH PERIPHERY PERKOTAAN Tomi Setiawan *, Haidar Adi M, Yames Pakniany, dan Indria R . Mutiar. 246-266. 